This is an electronic reprint of the original article. This reprint may differ from the original in pagination and typographic detail.

Author(s): Brown, Rudy M.; Garcia, Javier Borau; Valjus, Juuso; Roberts, Christopher; Tuononen, Heikki; Parvez, Masood; Roesler, Roland

Title: Ammonia Activation by a Nickel NCN-Pincer Complex featuring a Non-Innocent NHeterocyclic Carbene: Ammine and Amido Complexes in Equilibrium

Year: $\quad 2015$

Version:

Please cite the original version:

Brown, R. M., Garcia, J. B., Valjus, J., Roberts, C., Tuononen, H., Parvez, M., \& Roesler, R. (2015). Ammonia Activation by a Nickel NCN-Pincer Complex featuring a NonInnocent N-Heterocyclic Carbene: Ammine and Amido Complexes in Equilibrium. Angewandte Chemie International Edition, 54(21), 6274-6277.

https://doi.org/10.1002/anie.201500453

All material supplied via JYX is protected by copyright and other intellectual property rights, and duplication or sale of all or part of any of the repository collections is not permitted, except that material may be duplicated by you for your research use or educational purposes in electronic or print form. You must obtain permission for any other use. Electronic or print copies may not be offered, whether for sale or otherwise to anyone who is not an authorised user. 


\title{
Ammonia Activation by a Nickel NCN-Pincer Complex featuring a Non-Innocent N-Heterocyclic Carbene: Ammine and Amido Complexes in Equilibrium**
}

\author{
Rudy M. Brown, Javier Borau Garcia, Juuso Valjus, Christopher J. Roberts, Heikki M. Tuononen, \\ Masood Parvez, and Roland Roesler*
}

\begin{abstract}
An NCN-pincer complex of nickel(0), 3, featuring a sixmembered $\mathrm{N}$-heterocyclic carbene $(\mathrm{NHC})$ central platform and amidine pendant arms, was synthesized by deprotonation of its nickel(II) precursor, 2. It retained $\mathrm{Cl}^{-}$in the square planar coordination sphere of nickel and was expected to be highly susceptible to oxidative addition reactions. Complex 3 rapidly activated ammonia at room temperature, in a ligand-assisted process where the carbene carbon played the unprecedented role of proton acceptor. For the first time, the coordinated (ammine, 4) and activated (amido, $\mathbf{5}$ ) species were observed together in solution, in a solvent-dependent equilibrium. A structural analysis of $\mathbf{2}$ and $\mathbf{3}$ provided insight into the highly unusual, non-innocent behaviour of the NHC ligand.
\end{abstract}

The activation of ammonia at metal centers is believed to play a crucial step in the catalytic functionalization of organic substrates, most notably olefins. ${ }^{1}$ Unfortunately, conducting this reaction with a Lewis base as a substrate poses substantial difficulties related to the activation-coordination equilibrium, which in the vast majority of cases is completely shifted in favor of the latter. Early work on ammonia activation involved Till by Armor and $\mathrm{Zr}^{\prime \prime}$ by Bercaw, ${ }^{2}$ as well as $\mathrm{Os}_{3}(\mathrm{CO})_{12}$ by Lewis and Süss-Fink. ${ }^{3}$ Iridium took center stage in the activation of ammonia starting with Milstein's reports of oxidative addition of the $\mathrm{N}-\mathrm{H}$ bonds at $\mathrm{Ir}^{\mathrm{l}}$ to yield dinuclear, bridging amido complexes $L_{n}(H)\left|r^{\prime \prime \prime}\left(\mu-N_{2}\right)_{2}\right| r^{\prime \prime \prime}(H) L_{n} . \quad 4 \quad$ Similar chemistry was also investigated by Braun. ${ }^{5}$ Another significant development was the introduction of pincer complexes by Hartwig and later Turculet, who described the activation of ammonia on $\mathrm{Ir}^{l} \mathrm{PCP}$ and PSiP pincer complexes, respectively, to yield mononuclear, terminal $\mathrm{L}(\mathrm{H}) \mid \mathrm{r}^{\mathrm{II}}-\mathrm{NH}_{2}$ derivatives. ${ }^{6}$ Also notable is the homolytic ammonia activation by a dinuclear Pd' PNP pincer complex, reported by Ozerov, where a terminal $\mathrm{LPd}^{\prime \prime}-\mathrm{NH}_{2}$ species was obtained along with LPd" $-\mathrm{H}^{7}$

[*] R. Brown, Dr. J. Borau Garcia, Prof. M. Parvez, Prof. R. Roesler Department of Chemistry, University of Calgary

2500 University Dr. NW, Alberta, T2N1N4 Canada

E-mail: roesler@ucalgary.ca

Dr. J. Borau Garcia, current afiliation Secure Energy Services Inc., Bow Valley Sq. 2 1900, 205 5Th Ave SW, Calgary, Alberta, Canada. J. Valjus, C. J. Roberts, Dr. H. M. Tuononen

Department of Chemistry, Nanoscience Center

University of Jyväskylä, P.O. Box 35, FI-40014, Finland

[**] Financial support from the The Natural Sciences and Engineering

Research Council of Canada is acknowledged. H.M.T

acknowledges support from the Academy of Finland and the

University of Jyväskylä. This work was also supported in part by the

NSF Graduate Research Opportunities Worldwide Program (C.J.R).
Ammonia activation via metathesis, without formally changing the oxidation state of the metal, is well documented on several metals including $R u$ and $\mid \mathrm{Ir}^{1},{ }^{8}$ but can pose problems in terms of catalysis because the hydrogen is removed from the catalytic site. Milstein showed evidence for the heterolytic, deprotonative $\mathrm{N}-\mathrm{H}$ bond activation of ammonia using a $\mathrm{Ru}^{\mathrm{ll}}$ complex incorporating non-innocent PNP pincer ligands, without observing the corresponding $\mathrm{LRu}^{\mathrm{II}}-\mathrm{NH}_{2}$ species. ${ }^{9 \mathrm{a}}$ The similar, ligand-assisted cleavage of the $\mathrm{N}-\mathrm{H}$ bond in ammonia by an $\mathrm{Ir}^{\mathrm{l}}$ complex featuring a pyridyl-based PNP pincer ligand, to give a terminal LIr'- $\mathrm{NH}_{2}$ species, was described by Yoshizawa and Ozawa. ${ }^{9 b}$ A related ligand-assisted ammonia activation reaction was reported by Kuwata and Ikariya on a dinuclear $\operatorname{LIr}^{\prime \prime \prime}(\mu-H)(\mu-$ $\mathrm{NH}) \mid \mathrm{r}^{\prime \prime \prime} \mathrm{L}^{-}$compound, resulting in the formation of $\operatorname{LIr}^{\prime \prime \prime}(\mu-\mathrm{H})(\mu-$ $\left.\mathrm{NH}_{2}\right)_{2} \mid \mathrm{r}^{\mathrm{III}} \mathrm{L}^{-} .^{10}$ Piers recently disclosed the use of a carbenebased PCP-pincer complex of $\mathrm{Ni}^{0}$ for the ligand-assisted activation of ammonia to give a terminal $\mathrm{LNi}^{\prime \prime}-\mathrm{NH}_{2}$ product. ${ }^{11}$ Noteworthy are also the remarkable progresses made in the activation of ammonia by main group systems. ${ }^{12}$

The activation of the $\mathrm{N}-\mathrm{H}$ bond in ammonia proved to be highly sensitive to the nature of the catalyst, ${ }^{13}$ with the ammine-amide equilibrium being completely shifted upon changing the metal from rhodium (ammine) to iridium (amide) for the same ligand system. ${ }^{6 b}$ Moreover, the nature of the phosphine ligand was shown to have similar effects in iridium complexes. ${ }^{4 d}$ Homogeneous catalytic hydroamination with ammonia remains a major challenge, and notable progress towards this goal was the stoichiometric, intramolecular hydroamination of the coordinated ligand in an iridium amide complex. ${ }^{14}$

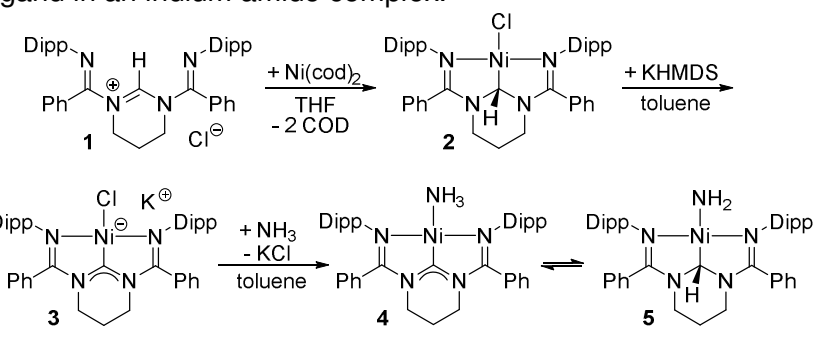

Scheme 1. Synthesis of derivatives 1 - 5.

Continuing our investigations of ammonia activation on pincer complexes incorporating NHC scaffolds, we report herein the reversible, ligand-assisted activation of ammonia on a $\mathrm{Ni}^{0}-\mathrm{NCN}$ pincer complex.

Pro-ligand $\mathbf{1}$ is similar to those reported by Byers and Lavoie and was prepared by the stepwise functionalization of 1,4,5,6tetrahydropyrimidine with $\mathrm{N}$-Dipp-benzimidoyl chloride (Dipp = 
2,6-diisopropylphenyl), using a modification of a reported procedure..$^{15}$ Its room temperature reaction with $\mathrm{Ni}(\mathrm{cod})_{2}(\mathrm{COD}=$ cycloocta-1,5-diene) produced a deep red solution, from which complex 2 was isolated as an orange solid in $67 \%$ yield (Scheme 1). The ${ }^{1} \mathrm{H}$ NMR spectrum of 2 revealed a $C_{\mathrm{s}}$ symmetry, instead of $C_{2 v}$ expected for a $\mathrm{Ni}-\mathrm{NHC}$ complex. A resonance corresponding to the $\mathrm{N}_{2} \mathrm{CH}$ proton appeared at $5.82 \mathrm{ppm}$,

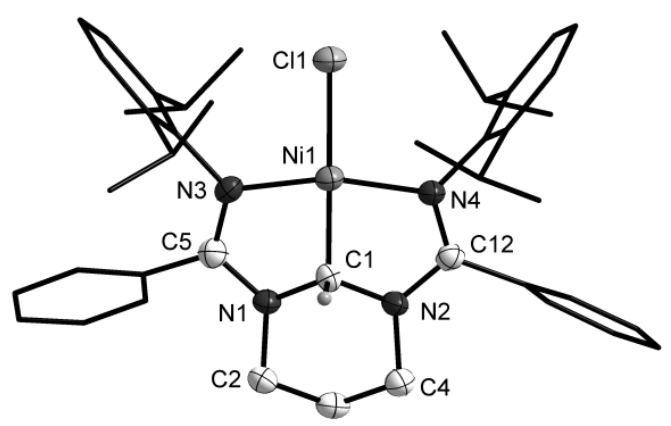

Figure 1. Structure of one of the two independent molecules of $\mathbf{2}$ in the solid state, with selected ellipsoids drawn at $50 \%$ probability. All hydrogen atoms except for the $\mathrm{N}_{2} \mathrm{CH}$ proton were omitted for clarity. Selected bond lengths $(\AA)$ and angles (ㅇ): Ni1-C1 1.848(5), Ni1-Cl1 2.222(1), Ni1-N3 1.914(4), Ni1-N4 1.914(4), N1-C1 1.440(6), N2-C1 1.439(6), C5-N3 1.312(6), C12-N4 1.305(6), C5-N1 1.340(6), C12-N2 1.352(6), N1-C1-N2 111.3(4), C1-Ni1-Cl1 175.0(2), N3-Ni1-N4 159.2(2).

substantially high-field shifted from $8.84 \mathrm{ppm}$ in 1 . The crystal structure confirmed the distorted tetrahedral geometry of the $\mathrm{N}_{2} \mathrm{CH}$ carbon on the NCN pincer complex, with the sum of the bond angles formed by the heavier elements at $\mathrm{C} 1$ measuring 332.5을 (Figure 1). With 1.848(5) $\AA$, the $\mathrm{C} 1-\mathrm{Ni1}$ bond is short when compared to similar bonds in nickel(II) pincer complexes featuring dialkylmethy ${ }^{16}$ or diarylmethyl ${ }^{11}$ central platforms (av. $\mathrm{Ni}-\mathrm{C}$ 1.98(2) and 1.986(3) $\AA$, respectively). Although the preference for alkyl vs. carbene coordination is common for complexes of dialkyl and diaryl carbenes, it is very rare for complexes of the more stable NHCs. Only few such examples have been structurally characterized to date, ${ }^{17}$ and we propose that the competitive delocalization of the nitrogen lone pairs onto the exocyclic amidine moieties is responsible for a reduced stabilization of the carbene structure..$^{18}$ In support of this theory, the two C-N bonds of each pendant amidine group in $\mathbf{2}$ are almost equal in length. Treatment with potassium hexamethyldisilazide in toluene yielded nevertheless the NHC complex 3 , with nickel retaining the chloride in its coordination sphere. The ${ }^{1} \mathrm{H}$ NMR spectrum of this $\mathrm{Ni}^{0}$ complex confirmed the disappearance of the resonance corresponding to the $\mathrm{N}_{2} \mathrm{CH}$ proton.

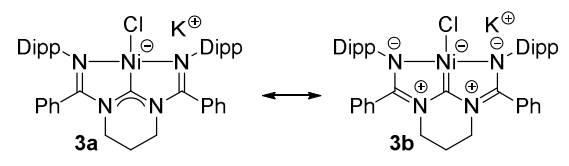

Scheme 2. Resonance structures $\mathbf{3 a}$ and $\mathbf{3 b}$
A crystal structure of 3 revealed a dimeric arrangement with two anionic $\mathrm{LNi}{ }^{\circ} \mathrm{Cl}$ moieties bridged by the potassium counterions (Figure 2). In turn, the $\pi$-coordination of the Dipp groups completes the distorted square planar coordination geometry of the potassium ions. The carbene carbon $\mathrm{C} 1$ is close to planarity, with a sum of bond angles of $350.8^{\circ}$. At $1.795(7) \AA$, the Ni1-C1 bond in $\mathbf{3}$ is shorter than in $\mathbf{2}$, and in fact shorter than all reported $\mathrm{Ni}^{0}-\mathrm{C}_{\mathrm{NHC}}$ bonds $(1.827(6)$ to $2.021(4) \AA$, av. 1.91(4) $\AA) .{ }^{19}$ The conversion to an NHC is accompanied by the expected shortening of the $\mathrm{C}-\mathrm{N}$ bonds to the carbene carbon, from $1.44 \AA$ in 2 to $1.39 \AA$ in 3 . These bonds remain nevertheless a bit long for in comparison to those observed in other $\mathrm{NHC}$ complexes (av. $1.36(2) \AA),{ }^{19}$ supporting a substantial contribution of resonance structure $\mathbf{3 b}$ (Scheme 2 ).

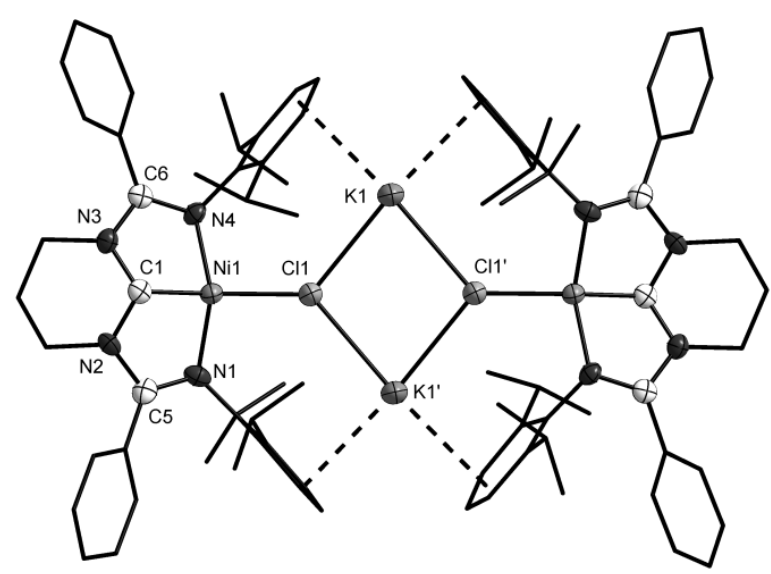

Figure 2. Structure of one of the two independent molecules of $\mathbf{3}$ in the solid state, with selected ellipsoids drawn at $50 \%$ probability. All hydrogen atoms were omitted for clarity. Selected bond lengths $(\AA)$ and angles $(\stackrel{\circ}{)})$ : Ni1-C1 1.795(7), Ni1-Cl1 2.296(2), Ni1-N1 1.913(6), Ni1-N4 1.903(6), N2-C1 1.395(9), N3-C1 1.392(9), C5-N1 1.361(10), C6-N4 1.364(9), C5-N2 1.380(10), C6-N3 1.355(10), Cl1-K1 2.948(3), Cl1-K1' 2.977(3), Ni2-C1-N3 117.3(4), C1-Ni1-Cl1 166.2(2), N1-Ni1-N4 155.7(3).

Complex 3 was expected to be prone to oxidative addition reactions upon elimination of $\mathrm{KCl}$. Exposure to ammonia gas at room temperature in either toluene or THF yielded immediately a dark solution. ${ }^{1} \mathrm{H}$ NMR spectroscopy indicated the presence of two compounds, one with $C_{2 v}$ and the other with $C_{\mathrm{s}}$ symmetry, which were assigned to $\mathbf{4}$ and $\mathbf{5}$, respectively. For the former compound, the ${ }^{1} \mathrm{H}$ NMR spectrum of the mixture displayed the two expected doublet resonances corresponding to the diastereotopic methyl groups of the ligand, and a resonance corresponding to the coordinated ammonia at $-0.11 \mathrm{ppm}$ in toluene- $d_{8}$ and 0.45 in THF- $d_{8}$. For the activation product 5 , the spectrum displayed four doublet resonances corresponding to the methyl groups of the ligand, and a resonance for the amide protons at $-2.97 \mathrm{ppm}$ in toluene- $d_{8}$ and $-3.63 \mathrm{ppm}$ in THF- $d_{8}$. Additionally, the signal corresponding to the $\mathrm{N}_{2} \mathrm{CH}$ proton was observed at $5.13 \mathrm{ppm}$ in toluene- $d_{8}$ and $5.22 \mathrm{ppm}$ in THF- $d_{8}$. The two structural isomers were present in $\mathbf{4}: \mathbf{5}$ ratios of $c a .4$ : 1 in toluene- $d_{8}$ and $2: 3$ in THF- $d_{8}$, with intermediate ratios in mixed-solvent systems, indicating that an equilibrium was present in solution (Figure 3). This was further confirmed by 
EXSY NMR spectroscopy, which showed cross-peaks between the signals corresponding to the $\mathrm{NH}_{3}$ protons in $\mathbf{4}$ and the $\mathrm{NH}_{2}$ and $\mathrm{N}_{2} \mathrm{CH}$ protons in $\mathbf{5}$ (see Supporting Information). Exposure of a solution of $\mathbf{4}$ and $\mathbf{5}$ in toluene- $d_{8}$ to $\mathrm{ND}_{3}$ resulted, as expected, in the rapid decrease of the intensity of the ${ }^{1} \mathrm{H}$ NMR signals corresponding to the $\mathrm{N}_{2} \mathrm{CH}, \mathrm{NH}_{3}$ and $\mathrm{NH}_{2}$ protons following the exchange with deuterium. Solvent removal from solutions containing $\mathbf{4}$ and $\mathbf{5}$ produced a highly sensitive microcrystalline dark green solid that could be stored for weeks at $-38{ }^{\circ} \mathrm{C}$ in the absence of air and moisture. Its identity could not be confirmed due to the insufficient quality of the single crystals. No distinctive IR bands corresponding to $\mathrm{N}-\mathrm{H}$ vibrations were observed. The solid redissolved in THF and toluene giving solutions that displayed properties identical to those observed for the solution of in-situ prepared $\mathbf{4 / 5}$.

Density functional theory calculations were performed on model compounds $4^{\mathrm{Ph}}$ and $5^{\mathrm{Ph}}$ in which the Dipp substituents were replaced by phenyl groups. The gas phase free energies of the optimized structures show that $4^{\text {Ph }}$ is favored over $5^{\text {Ph }}$ by 6 $\mathrm{kJ} \cdot \mathrm{mol}^{-1}$ in low dielectric media, in good agreement with the value of $3.4 \mathrm{~kJ} \cdot \mathrm{mol}^{-1}$ derived from the relative concentrations in toluene- $d_{8}$ solutions. When a continuum solvent model for THF was used, the calculations predicted $5^{\mathrm{Ph}}$ to be lower in energy than $4^{\mathrm{Ph}}$ by $21 \mathrm{~kJ} \cdot \mathrm{mol}^{-1}$. This matches less well the experimentally derived value of $1.0 \mathrm{~kJ} \cdot \mathrm{mol}^{-1}$, but it shows the same preference for $5^{\mathrm{Ph}}$.

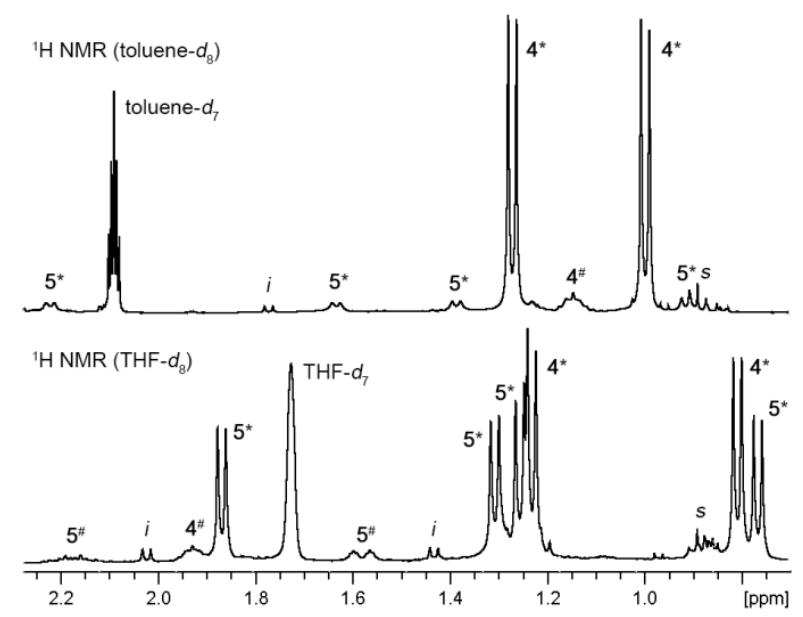

Figure 3. Selected range of the ${ }^{1} \mathrm{H}$ NMR spectra of the equilibrium mixture of 4 and 5 in toluene- $d_{8}$ (top) and THF- $d_{8}$ (bottom). The signs indicate: ${ }^{*}\left(\mathrm{CH}_{3}\right)_{2} \mathrm{CH}$, \# NHC backbone, $i$ unidentified impurity, $s$ solvent.

An equilibrium between coordinated (ammine) and activated (amido) ammonia complexes has been proposed before, mainly based on exchange experiments using $\mathrm{ND}_{3} \cdot{ }^{9 a},{ }^{11}$ However, in some systems the incorporation of deuterium was likely to be a result of mechanisms other than the reversible oxidative addition of ammonia. ${ }^{5 c, 6 b}$ The $\mathbf{4}$ - $\mathbf{5}$ system represents the first instance where the thermodynamic stability of the two complexes is comparable, allowing for the observation of both species in solution.
In conclusion, we report here a highly active $\mathrm{Ni}^{0}$ pincer complex that is able to reversibly activate ammonia at room temperature in a ligand-assisted process. Both coordinated (ammine, 4) and activated (amide, 5) coexist in solution in comparable, solventdependent proportions. The unprecedented ability of the sixmembered NHC in $\mathbf{3}$ to assist $\mathrm{N}-\mathrm{H}$ bond activation, accepting the proton at the carbene carbon, opens up a new page in the chemistry of this versatile family of compounds that have found widespread applications as ancillary ligands.

[1] a) T. Braun, Angew. Chem. 2005, 117, 5138-5140; Angew. Chem. Int. Ed. 2005, 44, 5012-5014; b) J. I. van der Vlugt, Chem. Soc. Rev. 2010, 39, 2302-2322.

[2] a) J. N. Armor, Inorg. Chem. 1978, 17, 203-213. b) G. L. Hillhouse, J. E. Bercaw, J. Am. Chem. Soc. 1984, 106, 5472-5478.

[3] a) E. G. Bryan, B. F. G. Johnson, J. Lewis, J. Chem. Soc. Dalton Trans. 1977, 1328-1330; b) G. Süss-Fink, Z. Naturforsch., Anorg. Chem., Org Chem. 1980, 35B, 454-457.

[4] a) A. L. Casalnuovo, J. C. Calabrese, D. Milstein, Inorg. Chem. 1987, 26, 971-973; b) R. Koelliker, D. Milstein, Angew. Chem. 1991, 103, 724-726; Angew. Chem. Int. Ed. Engl. 1991, 30, 707-709; c) R Koelliker, D. Milstein, J. Am. Chem. Soc. 1991, 113, 8524-8525; d) M. Schulz, D. Milstein, J. Chem. Soc. Chem. Commun. 1993, 318-319.

[5] a) M. Ahijado, A.-K. Jungton, T. Braun, Dalton Trans. 2009, 7669-7677. b) P. Kläring, S. Pahl, T. Braun, A. Penner, Dalton Trans. 2011, 67856791. c) A.-K. Jungton, P. Kläring, T. Braun, A. Eißler Z. Anorg. Allg. Chem. 2012, 638, 505-511.

[6] a) J. Zhao, A. S. Goldman, J. F. Hartwig, Science 2005, 307, 10801082; b) E. Morgan, D. F. MacLean, R. McDonald, L. Turculet, J. Am. Chem. Soc. 2009, 131, 14234-14236.

[7] C. M. Fafard, D. Adhikari, B. M. Foxman,D. J. Mindiola,O. V. Ozerov, J. Am. Chem. Soc. 2007, 129, 10318-10319.

[8] a) Y. Nakajima, H. Kameo, H. Suzuki, Angew. Chem., Int. Ed. 2006, 45, 950-952; Angew. Chem. 2006, 118, 964-966; b) I. Mena, M. A. Casado, P. García-Orduña, V. Polo, F. J. Lahoz, A. Fazal, L. A. Oro, Angew. Chem. 2011, 123, 11939-11942; Angew. Chem. Int. Ed. 2011, 50, 11735-11738, and references therein.

[9] a) E. Khaskin, M. A. Iron, L. J. W. Shimon, J. Zhang, D. Milstein, J. Am. Chem. Soc. 2010, 132, 8542-8543; b) Y. H. Chang, Y. Nakajima, H. Tanaka, K. Yoshizawa, F. Ozawa, J. Am. Chem. Soc. 2013, 135, 11791-11794.

[10] T. Kimura, N. Koiso, K. Ishiwata, S. Kuwata, T. Ikariya, J. Am. Chem. Soc. 2011, 133, 8880-8883.

[11] D. V. Gutsulyak, W. E. Piers, J. Borau-Garcia, M. Parvez, J. Am. Chem. Soc. 2013, 135, 11776-11779;

[12] a) G. D. Frey, V. Lavallo, B. Donnadieu, W. W. Schoeller, G. Bertrand, Science 2007, 316, 439-441; b) Y. Peng, B. D. Ellis, X. Wang, P. P. Power, J. Am. Chem. Soc. 2008, 130, 12268-12269; c) Z. Zhu, X. Wang, Y. Peng, H. Lei, J. C. Fettinger, E. Rivard, P. P. Power, Angew. Chem., Int. Ed. 2009, 48, 2031-2034; Angew. Chem. 2009, 121, 20652068; d) A. Jana, C. Schulzke, H. W. Roesky, J. Am. Chem. Soc. 2009, 131, 4600-4601; e) A. Meltzer, S. Inoue, C. Präsang, M. Driess, J. Am. Chem. Soc. 2010, 132, 3038-3046; f) J. Cui, Y. Li, R. Ganguly, A. Inthirarajah, H. Hirao, R. Kinjo J. Am. Chem. Soc. 2014, 136, 1676416767; g) S. M. McCarthy, Y.-C. Lin, D. Devarajan, J. W. Chang, H. P. Yennawar, R. M. Rioux, D. H. Ess, A. T. Radosevich J. Am. Chem. Soc. 2014, 136, 4640-4650 and references therein.

[13] A. Uhe, M. Hölscher, W. Leitner, Chem. Eur. J. 2013, 19, 1020-1027.

[14] I. Mena, M. A. Casado, V. Polo, P. García-Orduña, F. J. Lahoz, L. A. Oro, Angew. Chem. Int. Ed. 2014, 53, 9627 -9631; Angew. Chem. 2014, 126, $9781-9785$.

[15] a) H. Z. Kaplan, B. Li, J. A. Byers, Organometallics 2012, 31, 73437350 ; b) J. A. Thagfi, G. G. Lavoie, Organometallics 2012, 31, 73517358; c) J. A. Thagfi, G. G. Lavoie, Can. J. Chem. 2014, 92, 925-931; 
d) C. M. Manna, H. Z. Kaplan, B. Li, J. A. Byers, Polyhedron 2014, 84 160-167.

[16] a) A. Castonguay, C. Sui-Seng, D. Zargarian, A. L. Beauchamp, Organometallics 2006, 25, 602-608; b) V. Pandarus, D. Zargarian, Chem. Commun. 2007, 978-980; c) V. Pandarus, D. Zargarian, Organometallics, 2007, 26, 4321-4334. d) A. Castonguay, A. L. Beauchamp, D. Zargarian, Organometallics, 2008, 27, 5723-5732; e) A. Castonguay, D. M. Spasyuk, N. Madern, A. L. Beauchamp, D. Zargarian, Organometallics 2009, 28, 2134-2141; f) A. Castonguay, A. L. Beauchamp, D. Zargarian, Inorg. Chem. 2009, 48, 3177-3184; g) E. A. Gwynne, D. W. Stephan, Organometallics 2011, 30, 4128-4135.
[17] a) U. Burger, C. Perret, G. Bernardinelli, E. P. Kündig, Helv. Chim. Acta 1984, 67, 2063-2067; b) A. A. Danopoulos, N. Tsoureas, J. C. Green, Michael B. Hursthouse, Chem. Commun., 2003, 756-757; c) C. Romain, K. Miqueu, J.-M. Sotiropoulos, S. Bellemin-Laponnaz, S. Dagorne, Angew. Chem., Int. Ed. 2010, 49, 2198-2201; d) A. F. Hill, C. M. A. McQueen, Organometallics 2012, 31, 8051-8054.

[18] M. G. Hobbs, T. D. Forster, J. Borau-Garcia, C. J. Knapp, H. M. Tuononen, R. Roesler, New J. Chem. 2010, 34, 1295-1308.

[19] F. H. Allen, Acta Cryst. 2002, B58, 380-388. 